\title{
Recent advances of on-demand dissolution of hydrogel dressings
}

Hao Lu', Long Yuan ${ }^{3}$, Xunzhou Yu ${ }^{2}$, Chengzhou Wu ${ }^{4^{*}}$, Danfeng $\mathrm{He}^{2^{*}}$ and Jun Deng ${ }^{2^{*}}$

\begin{abstract}
Wound management is a major global challenge and a big financial burden to the healthcare system due to the rapid growth of chronic diseases including the diabetes, obesity, and aging population. Modern solutions to wound management include hydrogels that dissolve on demand, and the development of such hydrogels is of keen research interest. The formation and subsequent on-demand dissolution of hydrogels is of keen interest to scientists and clinicians. These hydrogels have excellent properties such as tissue adhesion, swelling, and water absorption. In addition, these hydrogels have a distinctive capacity to form in situ and dissolve on-demand via physical or chemical reactions. Some of these hydrogels have been successfully used as a dressing to reduce bleeding in hepatic and aortal models, and the hydrogels remove easily afterwards. However, there is an extremely wide array of different ways to synthesize these hydrogels. Therefore, we summarize here the recent advances of hydrogels that dissolve on demand, covering both chemical cross-linking cases and physical cross-linking cases. We believe that continuous exploration of dissolution strategies will uncover new mechanisms of dissolution and extend the range of applications for hydrogel dressings.
\end{abstract}

Keywords: Wound management, Wound dressing, On-demand dissolution, Hydrogel

\section{Background}

Wound healing is intrinsically and closely related to survival; wounds such as the diabetic foot ulcers that fail to heal can lead to a lower 5-year survival rate than some cancers (e.g., breast and prostate) $[1,2]$. Thus, many efforts have been devoted to developing new and effective strategies to promote wound healing. In clinical settings, the standard processes for wound treatment include as follows: (1) cleaning the wound, (2) debriding, (3) choosing suitable dressings for wound healing, and(4) binding the wound to avoid shedding of dressings [3]. Dressings have long been considered as a critical part of wound care, and many of dressings can indeed be useful for topical therapies. In addition to the traditional cotton gauze dressings, a myriad of new dressings that are made of biological materials can also be selected by the

\footnotetext{
* Correspondence: 2637056467@qq.com; dfhe0722@163.com; djun.123@163.com

${ }^{4}$ Department of Respiratory, Wuxi Country People's Hospital, Chongqing 405800, China

${ }^{2}$ Institute of Burn Research, South-West Hospital, State Key Lab of Trauma, Burn and Combined Injury, Third Military Medical University (Army Medical University), Gaotanyan Road No. 30, Shapingba District, Chongqing 400038, China

Full list of author information is available at the end of the article
}

clinicians. Over the past few decades, biomaterials and especially polymeric materials have rapidly become a key enabling technology in this push to develop advanced strategies for wound care [4-6]. Polymeric materials were mostly used as dressing to treat wounds, which can absorb wound exudates, prevent wound desiccation, and isolate the wound from the environment [6-8]. A range of commercially available polymer-based dressings, such as hydrocolloids, polymeric film, fibers, and hydrogels, have been widely used for the treatment [5, 9]. However, currently available dressings adhere to the wound, particularly burn wound surfaces, requiring cutting and mechanical debridement for a dressing change. This can lead to traumatization of newly epithelialized tissues, delayed healing, and personal suffering in the injured patient $[10,11]$. Additionally, changing a wound dressing takes a long time. For example, the average duration of a burn dressing change is almost an hour [10]. The dressing change for anesthesia can require even more time. More seriously, these painful dressing changes have to be conducted many times until an obvious improvement in the wound healing is observed. This means that opaque burn dressings in clinical applications should be

(c) The Author(s). 2018 Open Access This article is distributed under the terms of the Creative Commons Attribution 4.0 International License (http://creativecommons.org/licenses/by/4.0/), which permits unrestricted use, distribution, and 
changed every 2 days to observe the condition of wound and avoid excessive waste of dressings. In fact, doctors want to use transparent dressings to make it easier to monitor the condition of wound and to place it on the wound surface for a long time until it heals. If the wound is infected, the dressings are expected to be dissolved as soon as possible. The ideal dissolution time of dressings should be controlled within a few minutes, and the ideal time for dressing change is expected to be rapid. Consequently, strategies with gentler and less invasive approaches enable facile dressing change and avoid secondary damage.

Therefore, there is a critical unmet need for a topically applied material that (1) is easily applied and forms in situ, (2) is of sufficient mechanical flexibility to accommodate complex wound contours and volumes, (3) can be easily and atraumatically removed under controlled conditions for definitive surgical care, and (4) is non-toxic. In order to fulfill these requirements, the first dissolvable hydrogel dressings were introduced. These controlled dissolution of hydrogels is especially significant for (1) atraumatic removal after dressing function is completed, (2) targetable transit of sealed therapeutics (e.g., proteins, cells, and small molecules), and (3) customized administration of highly efficient agent [12]. Despite an intense research focus on dissolvable cross-linked hydrogel, little effort has been made to summarize these systems. Here, we will outline the recent advances in hydrogels that dissolve on demand for nursing wounds, as this rapidly evolving field continues to make important contributions to biomedicine.

\section{Review}

\section{Dissolvable cross-linked hydrogels}

Hydrogels have three-dimensional structure, cross-linked networks, and excellent hydrophilicity [13]. Generally, hydrogels can be classified as either physically or chemically cross-linked hydrogels (Fig. 1). The network of physically cross-linked hydrogels is formed via non-covalent forces, such as physically molecular entanglements, ionic forces, host-guest interactions, H-bonding, and hydrophobic forces [14]. Because their networks are formed and decomposed by stimuli, such as changes of $\mathrm{pH}$, ionic concentration, or temperature, physically cross-linked hydrogels can exhibit reversibility [15]. On the other hand, the networks of chemically cross-linked hydrogels are formed through covalent bonds [16]. These types of hydrogels can only be dissolved by adding a dissolving agent along with a chemical reaction. Compositionally, both natural polymers including commonly used collagen, hyaluronic acid (HA) and chitosan (CS), and synthetic polymers involving poly(vinyl alcohol), poly(ethylene glycol) (PEG), and poly(acrylic acid) are widely utilized to form the hydrogels [17-19].

In recent years, hydrogels have become attractive for wound healing applications owing to their biocompatibility, tunable biodegradability, and controllable mechanical properties [20-22]. Since the chemistries and performances of hydrogels are controllable and repeatable, synthetic hydrogels gain especially interests for wound care applications [23, 24]. These controllable features include mediating the hydrogel and dissolution rates $[25,26]$. In particular, the controlled dissolution of hydrogels is important for their atraumatic removal from the wound after their function is complete. Generally, the dissolution of chemically cross-linked hydrogels can be achieved by incorporating cleavable moieties though the approach of ester hydrolysis or enzymatic degradation [27, 28]. Compared with chemically cross-linked hydrogels, the physically cross-linked hydrogels can undergo phase transitions by changing the external environment without coupling agent, optical irradiation, or

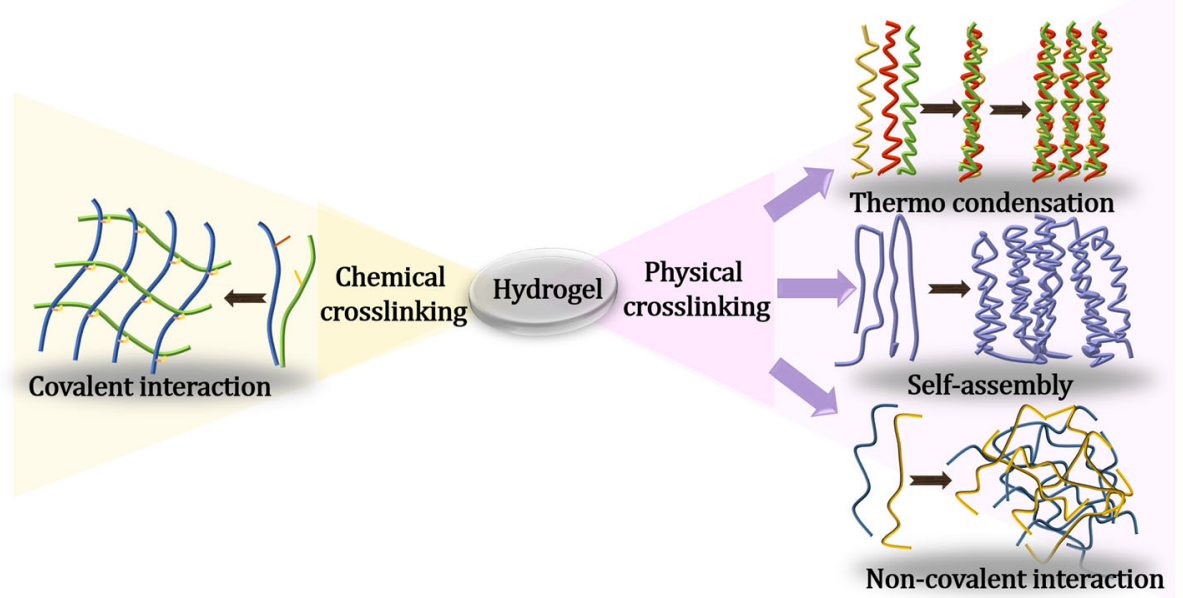

Fig. 1 Schematic illustration of hydrogels fabricated through chemically cross-linked or physically cross-linked 
organic solvents (which are usually harmful to the human body) [29-31]. However, mechanical properties of physically cross-linked hydrogels are weaker than chemically cross-linked hydrogels, so their application is limited [32, 33]. Consequently, we will review recent advances in developing dissolvable physically and chemically cross-linked hydrogels.

\section{Chemically cross-linked hydrogels}

Thiol-thioester exchange reaction, thiol-disulfide exchange reaction, retro-Michael reaction, and retro Diels-Alder (rDA) reaction have all been used to prepare dissolvable hydrogels. These hydrogels offer responsive synthetic processing for dissolution rates. Examples of these reactions as a method to synthesize on-demand dissolvable hydrogels are described below.

Thiol-thioester exchange Thiol-thioester exchange reaction can happen in water within biological $\mathrm{pH}$ ranges, which is mostly applied in self-assembly purposes where physiological conditions are required [34]. This type of reaction is based on the reaction between thiolate anion and thioester to produce other thiolates and thioester products (Fig. 2a). Moreover, carboxylic acids are formed due to the hydrolysis of thioesters during the competing process in water. The exchange speed and hydrolysis speed depend on the temperature and $\mathrm{pH}$ value of solution, as well as the acidity of the thiol-variant. For the fixed physiological environment, the rate-determining process during this type of reaction is decided by the relative $\mathrm{pK}_{\mathrm{a}}$ of entering and leaving thiols [35]. When the $\mathrm{pK}_{\mathrm{a}}$ of the conjugate acid in nucleophilic thiolate is greater than leaving thiolate, the rate-determining process occurs in the production of tetrahedral intermediate. Oppositely, when the $\mathrm{pK}_{\mathrm{a}}$ of conjugate acid in attacking thiolate is less than leaving thiolate, the rate-determining process occurs in the disintegration of tetrahedral intermediate. Notably, the reaction between thioester and nucleophilic oxygen is slower than the reaction between thioester and nucleophilic sulfur, which favors the production of thiol-thioester exchange products rather than hydrolysis [35].

Grinstaff et al. studied dissolvable hydrogels made by thiol-thioester exchange reaction [36, 37]. In particular, they studied a hydrophilic poly(ethylene glycol) lysine sulfhydryl (PEG-LysSH) dissolvable hydrogel-made stem from thiol-thioester exchange (Fig. 2b). To prepare the PEG-LysSH, the PEG amine $\left(M_{\mathrm{w}:} 2 \mathrm{kDa}\right)$ was introduced on the lysine-based peptide dendron possessing four

(A) Native chemical ligation(NCL)

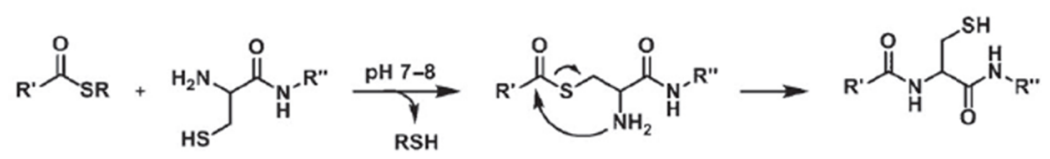

(B) Dissolution of PEG-LysSH hydrogel by NCL
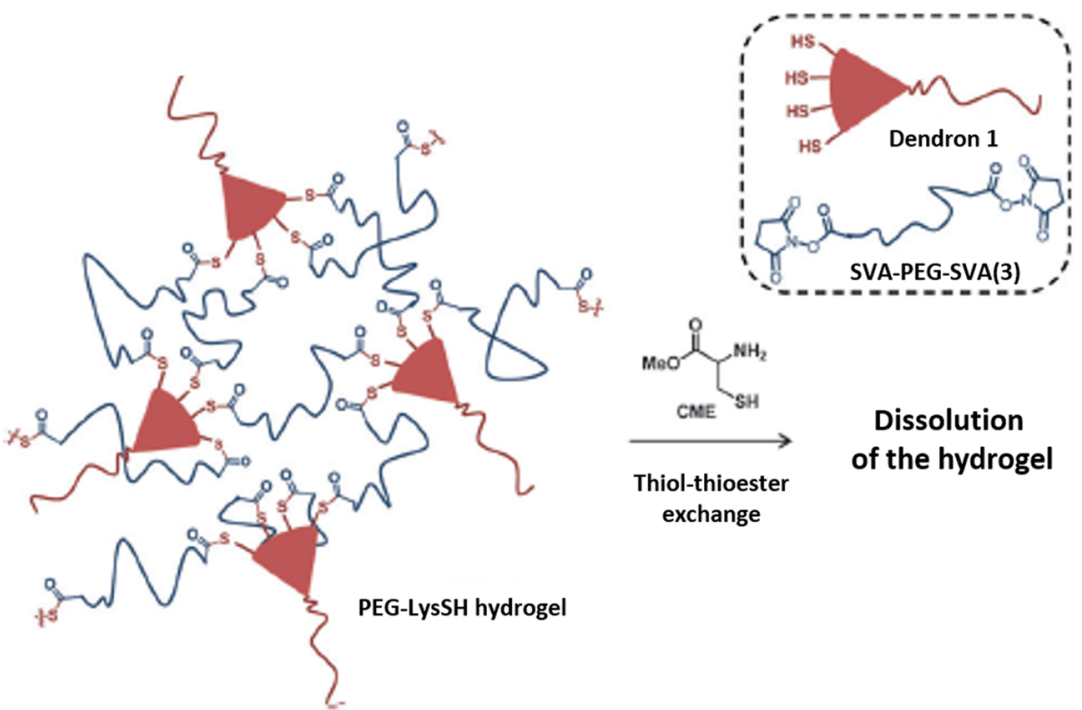

Thiol-thioester

Dissolution

of the hydrogel exchange

Fig. 2 Formation of poly(ethylene glycol) lysine sulfhydryl (PEG-lysSH) and subsequent dissolution. a Thiol-thioester exchange reaction [37]. b The example of a hydrophilic PEG-lysSH hydrogel dissolution based on thiol-thioester exchange. Figures are adapted with permission from the original articles of Ghobril et al. [37] (Copyright 2013 by Wiley-VCH Verlag GmbH \& Co. KGaA, Weinheim). CME cysteine methyl eater 
terminal thiols by a standard peptide coupling reaction. The dendritic molecules were composed of repeating nanoscale motifs, which were somewhere between polymers and a small organic molecule systems. Dendrons formed easily via a variety of non-covalent interactions, and they could provide a macromer with many reactive sites to ensure the fast formation of hydrogels [38]. The use of a dendritic macromonomer provides many advantages such as fine control of the composition, structure, and molecular weight. Then, the dissolvable thioester-linked PEG-LysSH hydrogel was fabricated spontaneously within seconds by mixing poly(ethylene glycol disuccinimidylvalerate) (SVA-PEG-SVA) with dendritic macromonomer with multiple reactive positions via native chemical ligation $(\mathrm{NCL})$ reaction $[39,40]$. The dissolution of PEG-LysSH-based hydrogel could occur in both L-cysteine methyl ester (CME) and 2-mercaptoethanesulfonate (MES) solutions. The dissolving mechanism of the hydrogel depended on thiol-thioester exchange reaction between the thioester bonds in hydrogel and thiolate solutions (e.g., CME, MES), and formed amide linkage to preclude re-formation of hydrogel. They found that the concentration of thiolate solutions and $\mathrm{pH}$ values had a significant effect on the dissolution behavior of PEG-LysSH hydrogel. The thioester bridges in the hydrogel could rapidly cleave, and the gel completely dissolved within $24 \mathrm{~min}$ at $\mathrm{pH} 8.5$ in $0.3 \mathrm{M}$ of MES solution. Since the hydrogel could be easily removed from the skin to avoid secondary damage, in vivo experiments had shown that this type of hydrogel possesses a potential application in wound repair. Recently, Konieczynska et al. synthesized a stimulus dissolvable dendritic thioester hydrogel burn dressing for second-degree burn healing [41]. The hydrogel was composed of a lysine-based dendron and a PEG-based cross-linker. Moreover, the lysine-based dendron used in the hydrogel was capped with nucleophilic amines, which could overcome the limited storage life and fine controllable gel rate that allows the matrix to easily fill the complex geometry of the burned area. They further studied the performance of on-demand dissolution of this hydrogel. After the hydrogel was applied to a second-degree burn wound on a rat and left to gel for $1 \mathrm{~h}$, a CME-soaked gauze was administered to half of the hydrogel for $30 \mathrm{~min}$, resulting in the dissolution of the gauze-treated hydrogel.

Overall, these works suggest that the on-demand dissolution of hydrogel based on thiol-thioester exchange provides a relatively inexpensive (Sigma Aldrich, $25 \mathrm{~g}$ of CME for \$28.60) and desirable alternative to debridement of the dressing. However, the thiols as hydrogel precursors are easily oxidized to disulfides, which results in the disactivation of the moiety in formation of hydrogel. Moreover, the toxicity of thiolate solution needs to be considered, and the dissolving and adhesive behavior of hydrogels in highly wet wound environment with high hydraulic pressure should be further studied. Herein, we summarize the main features, advantages, and disadvantages of these hydrogels in Table 1.

Table 1 Some of the main features of various crosslinking types of hydrogels. PBS phosphate buffer saline

\begin{tabular}{|c|c|c|c|c|c|c|c|}
\hline & Classification & $\begin{array}{l}\text { Exogenous } \\
\text { dissolution } \\
\text { agents }\end{array}$ & $\begin{array}{l}\text { In situ } \\
\text { formation } \\
\text { or not }\end{array}$ & $\begin{array}{l}\text { Expected } \\
\text { dissolution } \\
\text { time }\end{array}$ & $\begin{array}{l}\text { Potential } \\
\text { for wound } \\
\text { treatment }\end{array}$ & Advantages & Disadvantages \\
\hline \multirow{2}{*}{$\begin{array}{l}\text { Chemically } \\
\text { cross- } \\
\text { linked } \\
\text { hydrogels }\end{array}$} & $\begin{array}{l}\text { Stimuli-sensitive } \\
\text { hydrogels }\end{array}$ & Nothing & Yes & Immediately & $\begin{array}{l}\text { Better } \\
\text { application } \\
\text { in vivo }\end{array}$ & $\begin{array}{l}\text { Hydrogel are pure } \\
\text { and less toxic }\end{array}$ & $\begin{array}{l}\text { Low mechanical strength, less } \\
\text { crosslinking species, less selectivity of } \\
\text { polymer, long gelation time }\end{array}$ \\
\hline & $\begin{array}{l}\text { Supramolecular } \\
\text { self-assembly } \\
\text { hydrogels }\end{array}$ & $\begin{array}{l}\text { Mild } \\
\text { chemical } \\
\text { irrigant }\end{array}$ & Yes & $\begin{array}{l}\text { Within } 2 \\
\text { min }\end{array}$ & $\begin{array}{l}\text { Better } \\
\text { application } \\
\text { in vivo }\end{array}$ & $\begin{array}{l}\text { Hydrogels have better } \\
\text { mechanical properties } \\
\text { and less toxic effects }\end{array}$ & $\begin{array}{l}\text { Self-assembly process is difficult to } \\
\text { control }\end{array}$ \\
\hline \multirow{4}{*}{$\begin{array}{l}\text { Physically } \\
\text { cross- } \\
\text { linked } \\
\text { hydrogels }\end{array}$} & $\begin{array}{l}\text { Thiol-thioester } \\
\text { exchange }\end{array}$ & Thiolate & Yes & $\begin{array}{l}\text { Within } 25 \\
\text { min }\end{array}$ & $\begin{array}{l}\text { Better } \\
\text { application } \\
\text { in vivo }\end{array}$ & $\begin{array}{l}\text { A cheaper way for } \\
\text { hydrogel dissolution }\end{array}$ & $\begin{array}{l}\text { Dissolution times of hydrogel are too } \\
\text { long, and toxicity of thiolate is unknown }\end{array}$ \\
\hline & $\begin{array}{l}\text { Thiol-disulfide } \\
\text { exchange }\end{array}$ & $\begin{array}{l}\text { Thiol- } \\
\text { containing } \\
\text { reducing } \\
\text { agent }\end{array}$ & Yes & $\begin{array}{l}\text { Within } 10 \\
\text { min }\end{array}$ & $\begin{array}{l}\text { Better } \\
\text { application } \\
\text { in vivo }\end{array}$ & $\begin{array}{l}\text { Built-in redox- } \\
\text { sensitivity as living } \\
\text { cells }\end{array}$ & $\begin{array}{l}\text { Cytotoxicity of hydrogels or dissolution } \\
\text { agents are uncertainty }\end{array}$ \\
\hline & $\begin{array}{l}\text { Retro-Michael } \\
\text { reaction }\end{array}$ & $\begin{array}{l}\text { Glutamate, } \\
\text { PBS (pH } \\
7.4) \text {, or } \\
\text { light }\end{array}$ & Yes & $\begin{array}{l}2 \text { days } \\
\text { (glutamate); } \\
4 \text { days (PBS) } \\
4.5 \text { min } \\
\text { (light) }\end{array}$ & $\begin{array}{l}\text { Further } \\
\text { research is } \\
\text { needed }\end{array}$ & $\begin{array}{l}\text { Increased stability for } \\
\text { sustained release } \\
\text { under highly } \\
\text { reducing conditions }\end{array}$ & $\begin{array}{l}\text { Michael acceptors for retro Michael } \\
\text { Reaction have been less studied, and } \\
\text { the effect of hydrogel dissolution is } \\
\text { poor with side reaction }\end{array}$ \\
\hline & $\begin{array}{l}\text { Retro-Diels- } \\
\text { Alder reaction }\end{array}$ & $\begin{array}{l}\text { Dimethy } \\
\text { formamide }\end{array}$ & No & $\begin{array}{l}0.4 \mathrm{~h}\left(100^{\circ}\right. \\
\mathrm{C})\end{array}$ & $\begin{array}{l}\text { Further } \\
\text { research is } \\
\text { needed }\end{array}$ & $\begin{array}{l}\text { Hydrogels are formed } \\
\text { need no catalysts or } \\
\text { initiators }\end{array}$ & $\begin{array}{l}\text { The dissolution temperatures of } \\
\text { hydrogel are too high }\end{array}$ \\
\hline
\end{tabular}


Thiol-disulfide exchange The thiol-disulfide exchange reaction is important to many biological processes including the formation of cysteine disulfide bonds and disulfide mediated redox reactions [42, 43]. Typically, thiol-disulfide exchange contains three reversible steps (Fig. 3a): (1) ionization of thiol to thiolate anion in basic medium, (2) thiolate anion attack on the sulfur atom of the disulfide moiety via $\mathrm{SN}_{2}$ mechanism, and (3) protonation of thiolate anion. Due to its reversibility, the thiol-disulfide exchange has attracted interest in mediating changes in the modulus of hydrogels. The disulfide bond is a popular dynamic covalent bond that can respond to light stimulus and redox reagents [44]. Generally, the reversible thiol-disulfide exchange reaction can be triggered with excess thiolate and lofty $\mathrm{pK}_{\mathrm{a}}$.

Early preparations of on-demand disolving hydrogel according to thiol-disulfide exchange reaction were described by Hisano et al. [45]. The soluble poly (acrylamide-co- $N, N^{\prime}$-bisacrylcystamine) (P-S-S-P) hydrogel was formed through air oxidation of the thiols to disulfide bonds $(24 \mathrm{~h})$ or thiol-disulfide exchange reaction with poly(acrylamide-co- $N$-acryl-cysteamine) (P-SH) and low molecular weight disulfides (3,3'-dithiodipropionic acid, glutathione disulfide, or cystamine) [45]. L-cysteine or glutathione (GSH) molecules were used to dissolve this hydrogel via thiol-disulfide exchange reaction (Fig. 3b). The dissolution time of hydrogel reduced with the increase of the concentrations of L-cysteine or GSH, and the hydrogel could be dissolved within 1 min by adding the L-cysteine or GSH at a concentration of $600 \mu \mathrm{mol} / \mathrm{mL}$. Recently, Szilagyi et al. developed a redox-responsive disulfide cross-linked polysuccinimide (PSI) gels, which showed a reversible dissolution and gelation performance based on thiol-disulfide exchange reaction in a shorter time [46]. The PSI gels were dissolved within 15 min with the reducing agent of dithiothreitol at $1 \mathrm{mM}$, and the regelation phenomenon occurred with the PSI gels were oxidized in air to disulfide linkages within 4-6 h.

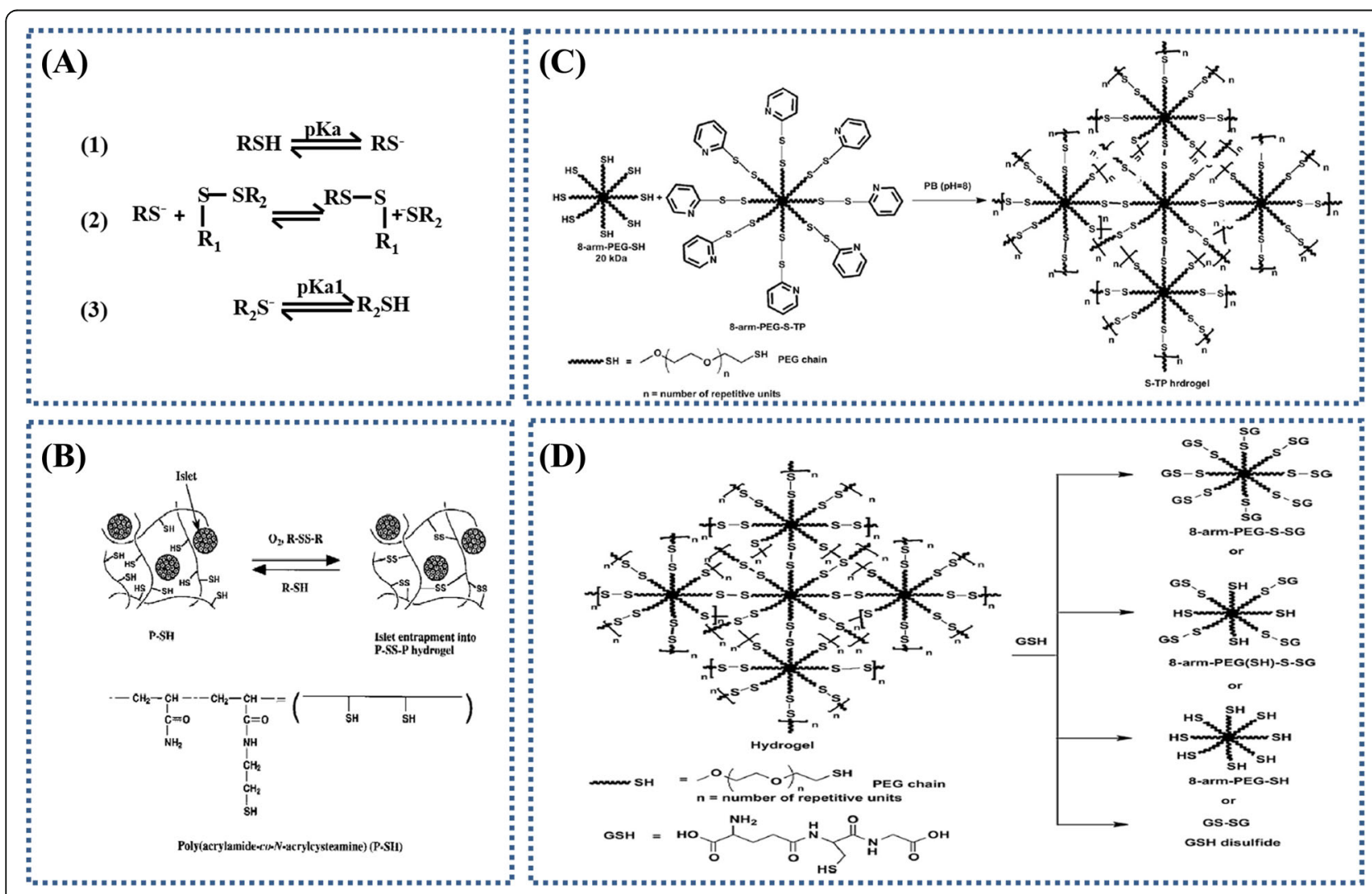

Fig. 3 Thiol-disulfide exchange reaction based hydrogels formation and theirs dissolution. a Thiol-disulfide exchange reaction. Figure is adapted with permission from the original articles of Houk and Whitesides [43] (Copyright 1987 by Amerian Chemical Society). b Reaction scheme for hydrogel preparation and its reliquefaction. Figure is adapted with permission from the original articles of Hisano et al. [45] (Copyright 1988 by John Wiley \& Sons, Inc.). c Schematic representation of thiopyridyl terminations appended on the 8-arm-poly(ethylene glycol) (PEG)-SH to form 8arm-PEG-S-TP. Thiopyridine is a good leaving group and the 8-arm-PEG-S-TP forms disulfide bridges with the 8-arm-PEG-SH in phosphate buffer (PB) $(\mathrm{pH} 8)$ resulting in S-TP hydrogels [47]. $\mathbf{d}$ Schematic of the reversible nature of hydrogels. Glutathione (GSH) acts as a thiolate moiety and attacks the disulfide bonds resulting in the breakdown of the hydrogel network (gel to sol transition). The possible products are 8-arm-PEG-SH, 8arm-PEG-(SH)-S-SG, 8-arm-PEG-S-SG and GS-SG. Figures are adapted with permission from the original articles of Anumolu et al. [47].(Copyright 2010 by Elsevier Ltd.) 
Anumolu et al. [47] designed analogous, and better hydrogels, which were composed of 8-arm-PEG-SH and either $\mathrm{H}_{2} \mathrm{O}_{2}$ or 8-arm-PEG-sulfur-thiopyridine (Fig. 3c). The hydrogels were in situ cross-linked in phosphate buffer saline (PBS) (pH 8.0) within $60 \mathrm{~s}$ and $10 \mathrm{~s}$, respectively. GSH was added as the thiolate moiety to leave extant disulfide bonds (Fig. 3d) [47]. The hydrogels were dissolved within 30-40 min, 15-20 $\mathrm{min}$, and $10-15 \mathrm{~min}$ in the presence of the $1 \%, 3 \%$, and $5 \%(w / v)$ glutathione solutions, respectively.

All of these works provide ways to synthesize on-demand dissolvable hydrogels according to thiol-disulfide exchange with the goal of wound dressing application. Unfortunately, as shown in Table 1, there are little data to speak to the toxicity of the dissolution agents. One more problem is that the thiol-containing hydrogel precursors are easily oxidized in air, causing trouble for the stable synthesis of the hydrogels.

Retro-Michael reaction The on-demand dissolution hydrogels can also be fabricated by retro-Michael reaction. One of the common retro-Michael reaction-based hydrogels use maleimide (MAL)-functionalized macromolecular monomers crosslinking with many thiol-functionalized multi-arm polymers to form a network crosslinking with thioether connections. The dissolution mechanism of the retro-Michael reaction-based hydrogels consists of covalent bond shift from original succinimide thioether compounds to jarless GSH conjugate with substantial reducing agents (Fig. 4a). The rate and degree of the dissolution reaction are regulated though the retro-addition rate, which are controlled via modulating the activity of the Michael donor. Typically,

(A)

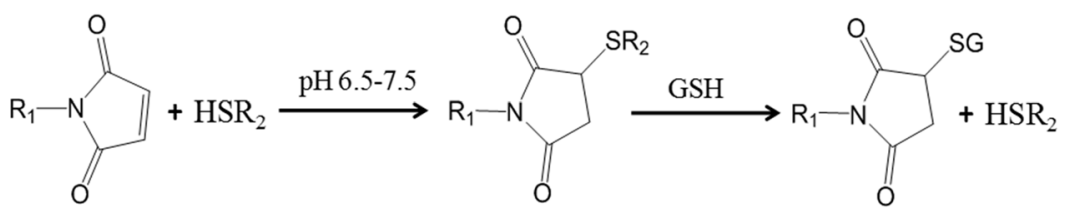

Hydrogel synthesis via thioether bond formation and dissolution via addition of GSH

(B)

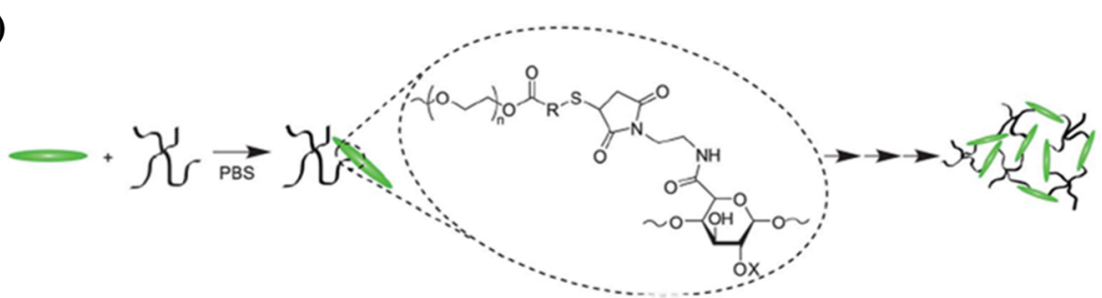

Hydrogel formation using Mal-LMWH and PEG-thiols

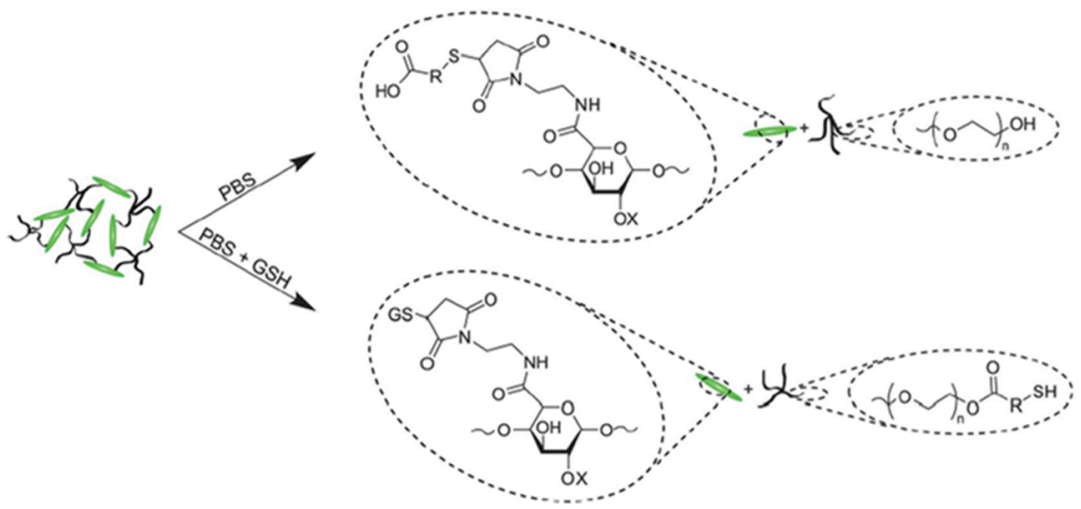

Degradation mechanisms for ester and succinimide thioether groups

Fig. 4 Formation and dissolution of hydrogel based on retro-Michael addition reaction. a Michael addition and retro-Michael reaction. Figure is adapted with permission from the original articles of Konieczynska and Grinstaff [36] (Copyright 2017 by American Chemical Society). b Hydrogel formation using maleimide-functionalized low-molecular weight heparin (MAL-LMWH) and poly(ethylene glycol) (PEG)-thiols; degradation mechanisms for ester and succinimide thioether groups. Figure is adapted with permission from the original articles of Baldwin and Kiick [48] (Copyright 2013 by Royal Society of Chemistry). GSH glutathione, PBS phosphate buffer saline 
a Michael donor with lofty $\mathrm{pK}_{\mathrm{a}}$ can be used to dissolve the hydrogel rapidly in reductive condition, while the retro reaction will be blocked in the case of the Michael donor with a high enough $\mathrm{pK}_{\mathrm{a}}$.

One example of the dissolvable hydrogels based on succinimide-thioether cross-linking was formed in situ by using a mixture of thiolated 4-arm-PEG $\left(M_{\mathrm{w}}: 10 \mathrm{kDa}\right)$ and MAL-functionalized low-molecular weight heparin (MAL-LMWH) (Fig. 4b) [48]. With the addition of $\mathrm{GSH}$, the hydrogels were dissolved, and the dissolution rate was governed by the reducing conditions [48]. In another recent report, Kiick et al. investigated an on-demand dissolvable hydrogel, which could be fabricated in situ within seconds via a Michael-type addition reaction [49]. The hydrogel was then dissolved though three different modes: GSH-reducing environment, photocleavage (visible and two-photon infrared light), and ester hydrolysis [49, 50]. Compared with disulfide-based hydrogels, these succinimide-thioether bond containing hydrogels exhibit higher stability. Current reports on the preparation of dissolvable hydrogels based on retro-Michael reaction focus on precursors containing maleimide, and more Michael acceptors (e.g., acrylates) for preparation of these hydrogels also need to be studied.

Retro-Diels-Alder reaction Another type of on-demand dissolvable hydrogels is based on Diels-Alder (DA) reactions and rDA reactions, and these reactions are reversible by temperature (Fig. 5a) [51]. Generally, DA reaction-based hydrogels are prepared in a reaction medium of water by the highly specific cyclization reaction of substituted alkene dienophile with conjugated diene. The reversible reaction-based hydrogels require high temperature to break the bond and dissolve. Moreover, the dissolution of these hydrogels requires many $\mathrm{rDA}$ reactions to happen synchronously at a fast rate. These effects limit their translation into biological milieus. Thus, there is interest in a new type of hydrogel systems with high reactivity to overcome the drawbacks above.

Wei et al. reported a dissolvable hydrogel that could be prepared via DA cyclization, and it could be dissolved at above $70^{\circ} \mathrm{C}$ via $\mathrm{rDA}$ reactions by exposing it to dimethylformamide (DMF) [52]. In order to make this class of functional hydrogels apply in a physiologically

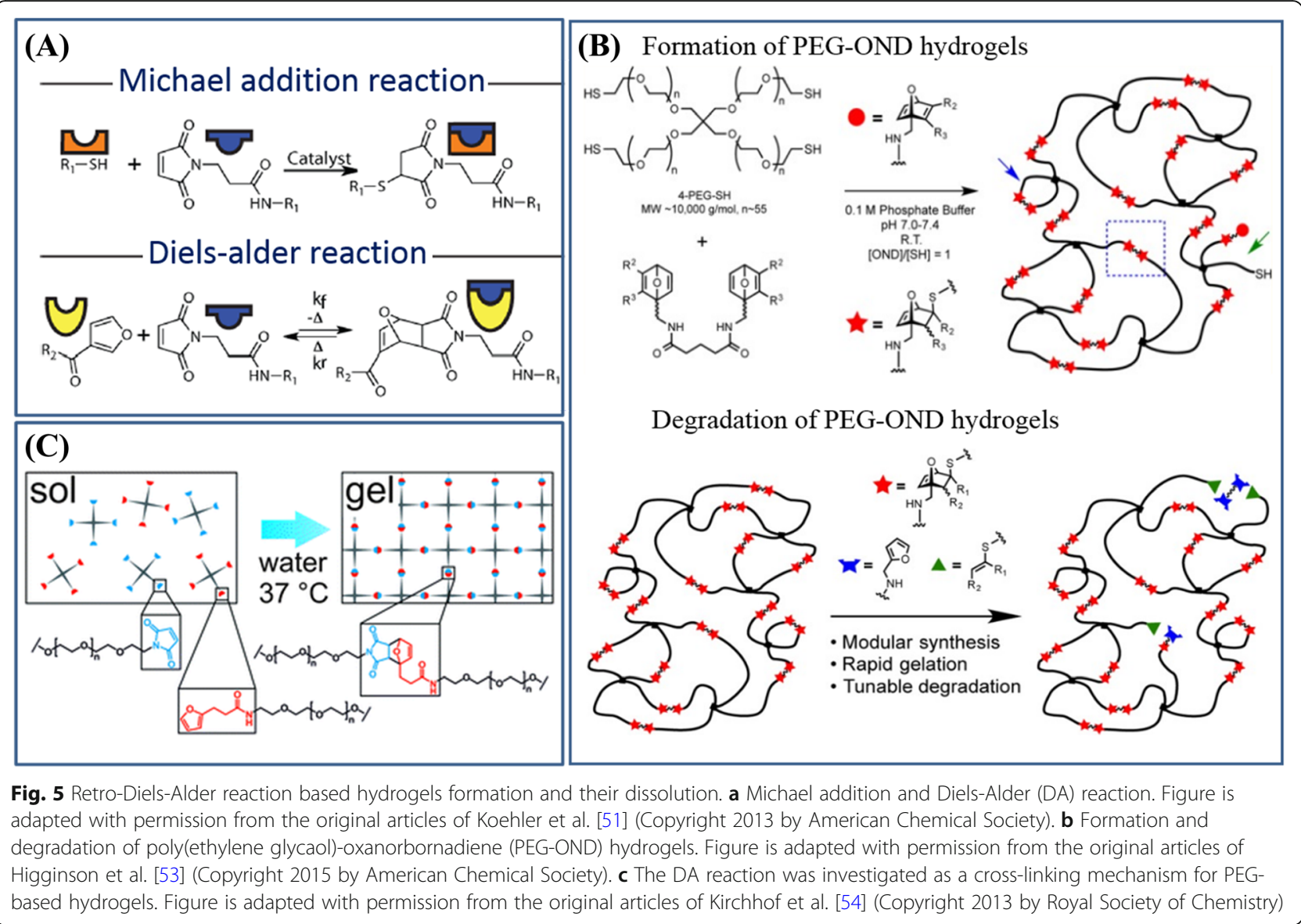


relevant environment, Finn et al. prepared the PEG-oxanorbornadiene (OND) hydrogels that could be dissolved in more than 1 day in a biologically relevant environment via rDA-mediated reactions (Fig. 5b) [53]. The hydrogel was synthesized via the reaction between 4-arm thiol-terminated PEG $\left(M_{\mathrm{w}}: 10 \mathrm{kDa}\right)$ and 7-OND cross-linkers. Interestingly, the authors observed that its dissolution rate was related to the temperature and OND moiety without swelling buffer, which was not related to $\mathrm{pH}$ values (5.0-9.0) during swelling process. Another related study of the dissolvable hydrogel with DA reaction was reported by Kirchhof et al. [54]. The DA hydrogel was prepared by mixing equimolar amounts of furyl and MAL substituted multi-arm PEGs [54] (Fig. 5c). Moreover, the gelation time and mechanical properties of the DA hydrogel were related to the concentration of polymer, branching amount, and molecular weight of PEGs [54]. The dissolution of hydrogel was triggered by the hydrolysis of chemically inert meleamic acid derivatives, and the process usually needs days to weeks [54].

Although there are other reversible open-loop addition reactions that are similar to the DA reaction and can be used to prepare dissolvable hydrogels, most can only be dissolved under radiation of the ultraviolet light (100$315 \mathrm{~nm}$ ), which is harmful to humans [55]. As shown in Table 1, the DA/rDA transformations provide an efficient, economical, and simple method for the formation and dissolution of hydrogels (e.g., the dissolution of hydrogels does not require any exogenous agents at elevated temperature). The slow dissolution of these hydrogels at biologically relevant conditions severely limits their biological applications.

\section{Physically cross-linked hydrogels}

The formation of physically cross-linked hydrogels is based on the physical interactions (e.g., ionic and hydrophobic associations) without any toxic cross-linking agents [56, 57]. This type of hydrogel can be reversed by the physical interactions between the molecular chains, and such hydrogels are typically safe in clinical applications [58]. Some physically cross-linked hydrogels can undergo volume or gel-sol phase reversible transitions in response to environmental stimuli, as shown in Fig. 6 [59]. Hydrogels containing such "sensor" properties have vast application prospects in biomedical fields because they can be removed atraumatically from wounds and because they are biodegradable. In general, the phase transition from gel to sol of physically cross-linked hydrogels is a slow process (which is usually called dissolution process). At present, different dissolution mechanisms have been proposed to explain the dissolution of all kinds of polymers, and the process can be roughly divided into two stages of swelling and dissolution [60,61]. The dissolution of crystalline or semicrystalline hydrogels is accompanied by a decrease in the degree of crystallinity until disappearing [62]. The time required for complete dissolution is related to the molecular weight, crystallinity, and other factors of hydrogels, and the time ranges from several seconds to several weeks. However, the clinical application of traditional physically cross-linked hydrogels still faces the problem of uncontrollable dissolving and poor mechanical properties [63]. What is exciting is that the invention of supramolecular hydrogels in recent years may overcome these shortcomings [64].

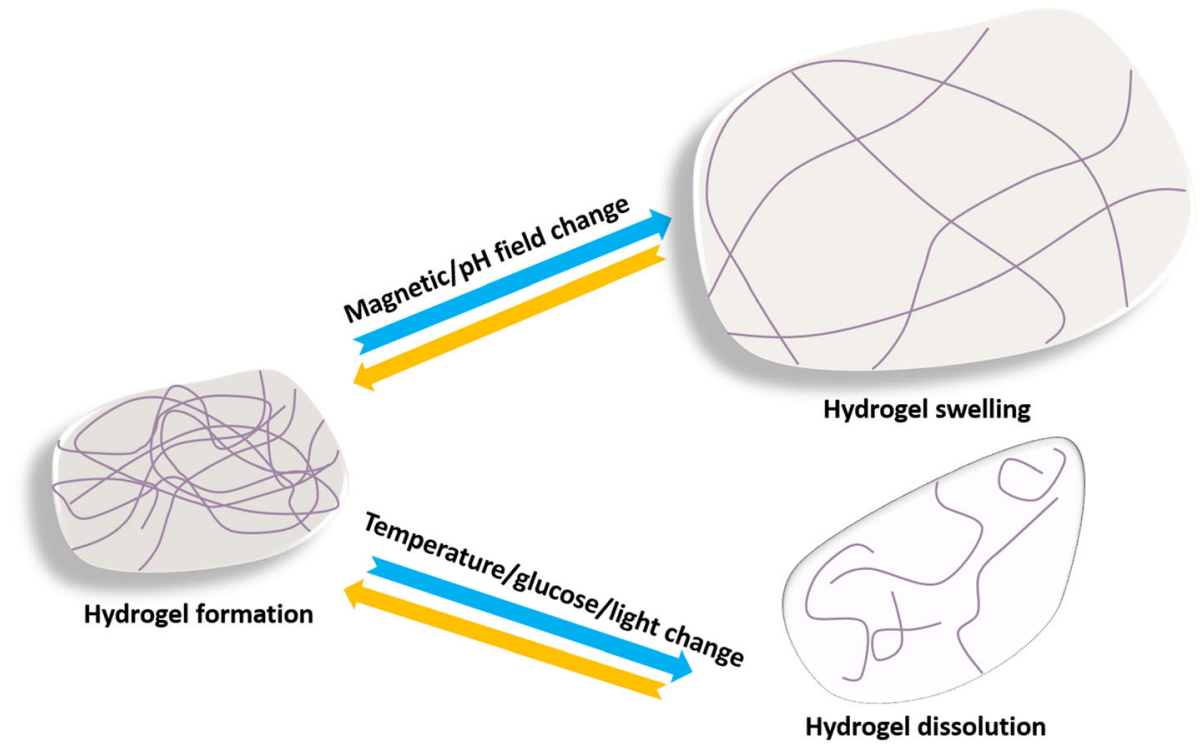

Fig. 6 Schematic illustration of the dissolution or swelling behavior of stimuli sensitive physically cross-linked hydrogels 
Supramolecular hydrogels are also often sensitive to the environment, and the dissolution of these hydrogels via stimulus is an ideal method for preventing secondary injury in wound care $[65,66]$. The recent progress of stimuli-dissolving traditional physically cross-linked hydrogels and supramolecular hydrogels are summarized in this section.

Temperature-sensitive physically cross-linked hydrogels (TPCH) Many environmental stimuli have been used to induce the volume or phase reversible transitions of the hydrogel systems, including $\mathrm{pH}$, temperature, ions, electric fields, light, pressure, sound, and magnetic fields $[67,68]$. Recently, the gel-sol phase reversible transitions of temperature-sensitive physically cross-linked hydrogels have been widely studied $[69,70]$. Here, the TPCH are mainly introduced.

The temperature-sensitive behavior of physically cross-linked traditional hydrogels means that they can change their hydrophilicity, hydrophobicity, and volume of gel networks. They can also undergo gel-sol reversible transitions with the change of temperature [71]. The polymer chains in TPCH can undergo sol-gel phase reversible transitions, which are sol at low temperature and gel at high temperature [72]. Typical TPCH are composed of hydrophobic chains (e.g., poly( $N$-isopropylacrylamide)) and hydrophilic links (e.g., poly(tetramethyleneether glycol)), and their molecular architecture may include two-block, three-block, multi-block, and hyperbranched structures [73]. The polymers can form a semi-rigid gel through the hydrophobic interactions or secondary bonding, and these bonds between the polymer chains can be changed with increased temperature [74]. TPCH can undergo the hydrophilic-hydrophobic transition via the hydrophobic interaction when temperature is above the lower critical solution temperature (LCST) [75]. The polymer solution has the low viscosity at room temperature, but it will turn into gel when the temperature is above the LCST. LCST values can be adjusted by changing the ratio of hydrophobic chain, hydrophilic chain, and molecular weight [76]. Generally, $\mathrm{TPCH}$ are significant for wound care because they can be removed easily from the wound at a temperature below human physiological temperature $\left(37^{\circ} \mathrm{C}\right)$.

One example of TPCH preparation is a physical mixture of chitosan and glycerol phosphate (GP) disodium salt [77]. The mixture remains in a transparent liquid state at room temperature, while gelation occurs at $37^{\circ}$ C. The gelation occurs because phosphates in GP neutralizes the amine groups of chitosan, leading to a rise in hydrophobic and hydrogen bonding between chitosan chains at a high temperature. Bhattarai et al. introduced an injectable chitosan-PEG (45-55 wt\%) TPCH, which took advantages of the interactions among chitosan chains for gelation [68]. The chitosan-PEG co-polymer was synthesized by chemically grafting monohydroxy PEG onto chitosan backbone via Schiff base and sodium cyanoborohydride chemistry. The mixture could be injected using a 22-G needle below the transition temperature, and gelation occurred at approximately $25^{\circ} \mathrm{C}$. The hydrogen bonds between PEG and water molecules are dominant at low temperatures, while the hydrophobic interactions between the polymer chains are dominant at high temperatures [78, 79], leading to the formation of hydrogels by the hydrophilic-hydrophobic transition. As wound dressing, this temperature-sensitive hydrogels can be dissolved on demand just by changing the temperature. Moreover, chitosan is able to promote faster wound healing and generate smooth scarring because of the enhancement of vascularization and the supply of chitooligomers at the lesion site [80, 81].

Such polymers can be used as an injectable hydrogels for treating the irregularly shaped wound; they can be injected around the wound at low temperatures, forming a gel at human physiological temperature. They can also be used as an in-situ gel sealant for emergency wound treatment, which can rapid gelation to attaching to the wound and be removed easily before subsequent treatment. However, as is shown in Table 1, one of the big problems is that the gelation time is rather long. Moreover, the dissolved temperature of TPCH should be further optimized.

Other stimuli sensitive physically cross-linked hydrogels In addition to the wide application of TPCH discussed above, other stimuli have also been used for preparing dissolvable hydrogels with environmental sensitivity. However, the preparation of hydrogels purely on the basis of physical cross-linking is rare, and the variety of polymers is limited. Nevertheless, there are several other stimuli-sensitive physically cross-linked dissolving hydrogels that have been studied. For example, the $\mathrm{pH}$ values can affect swelling or shrinkage behavior of $\mathrm{pH}$-sensitive hydrogels, because the pendant acidic (e.g., carboxylic acids) or basic (e.g., ammonium salts) groups in solution can accept or release protons with the change of $\mathrm{pH}$ values [72, 82]. These kinds of hydrogels have been most widely used in the field of controlled drug delivery and permeation switches [82]. Glucose-sensitive hydrogels can undergo sol-gel phase reversible transitions depending on the glucose concentration in the environment [72]. Some glucose-sensitive hydrogels can be formed by a reversible crosslink among the glucose-containing polymer chains via the non-covalent interaction between concanavalin A (Con A) and glucose. The glucose binding sites in Con A can combine free glucose or polymer-bound glucose depending on the concentration of free glucose [83]. Magnetic-sensitive hydrogels 
may undergo phase transitions via a magnetic field, and one way to obtain such hydrogels is to add magnetic nanoparticles [84]. Light-sensitive hydrogels are usually synthesized by introducing photo-responsive groups (e.g., azobenzene) [85, 86]. The self-assembly structure of the light-sensitive hydrogels can be destroyed with molecular isomerization upon ultraviolet irradiation; therefore, most of these hydrogels can undergo sol-gel phase transitions in the response process [87].

Supramolecular self-assembly hydrogels Supramolecular hydrogels are developed by employing noncovalent interactions (e.g., electronic, host-guest, and hydrophobic interactions) between components [88]. Supramolecular hydrogels often feature reversible, adaptive, stimuli-responsive, self-healing, and degradable properties due to the dynamic nature of noncovalent interactions [89]. Typically, supramonomers are bifunctional monomers that are prepared by noncovalent synthesis, but they also can undergo traditional covalent polymerization [90]. Supramonomers can also be used as cross-linkers to fabricate supramolecular hydrogels that respond to stimulus (i.e., temperature, light, $\mathrm{pH}$, electric field and oxidation reduction) and degradable properties. Since its unique dynamic and degradable properties, supramolecular hydrogels have been used as wound dressings that will be capable of dissolution according to the demand. Recently, researchers have been working on the stimuli sensitivity of the gel-sol phase reversible transitions of supramolecular hydrogels. For example, poly( $N$-isopropyl acrylamide) (PNIPAM) is often used to prepare temperature-sensitive supramolecular hydrogels. This system features hydrophilic amide group and hydrophobic isopropyl groups [91]. In addition, the supramolecular hydrogel [92], which is connected by $\beta$-cyclodextrin ( $\beta$-CD) and PEG, has an excellent temperature sensitivity. The transition can be repeated multiple times without significant modulus loss. In recent years, the researches on ultraviolet-visible-sensitive supramolecular hydrogels have received wide attention $[93,94]$. The most typical example consists of host molecule (e.g., cyclodextrin) and guest molecule (i.e., azobenzene and its derivatives). Such a hydrogel can undergo gel-sol phase reversible transitions with the irradiation of ultraviolet or visible light. Azobenzene can isomerize under ultraviolet or visible light, which will cause changes in the whole hydrogel system [95]. The host-guest interactions between the tripeptide (Phe-Gly-Gly) ester derivative and cucurbit [8] uril (CB[8]) were employed to synthesize supramolecular cross-linkers with one acrylate moiety at each end [96]. Then, supramolecular hydrogels were fabricated by copolymerization of acrylamide (AAm) with the above supramolecular cross-linkers (Fig. 7) [96]. Similar to the traditional chemically cross-linked hydrogels, the supramolecular hydrogels are biocompatible, soft, elastic, water-absorbant, and capable of being loaded with therapeutic agents.

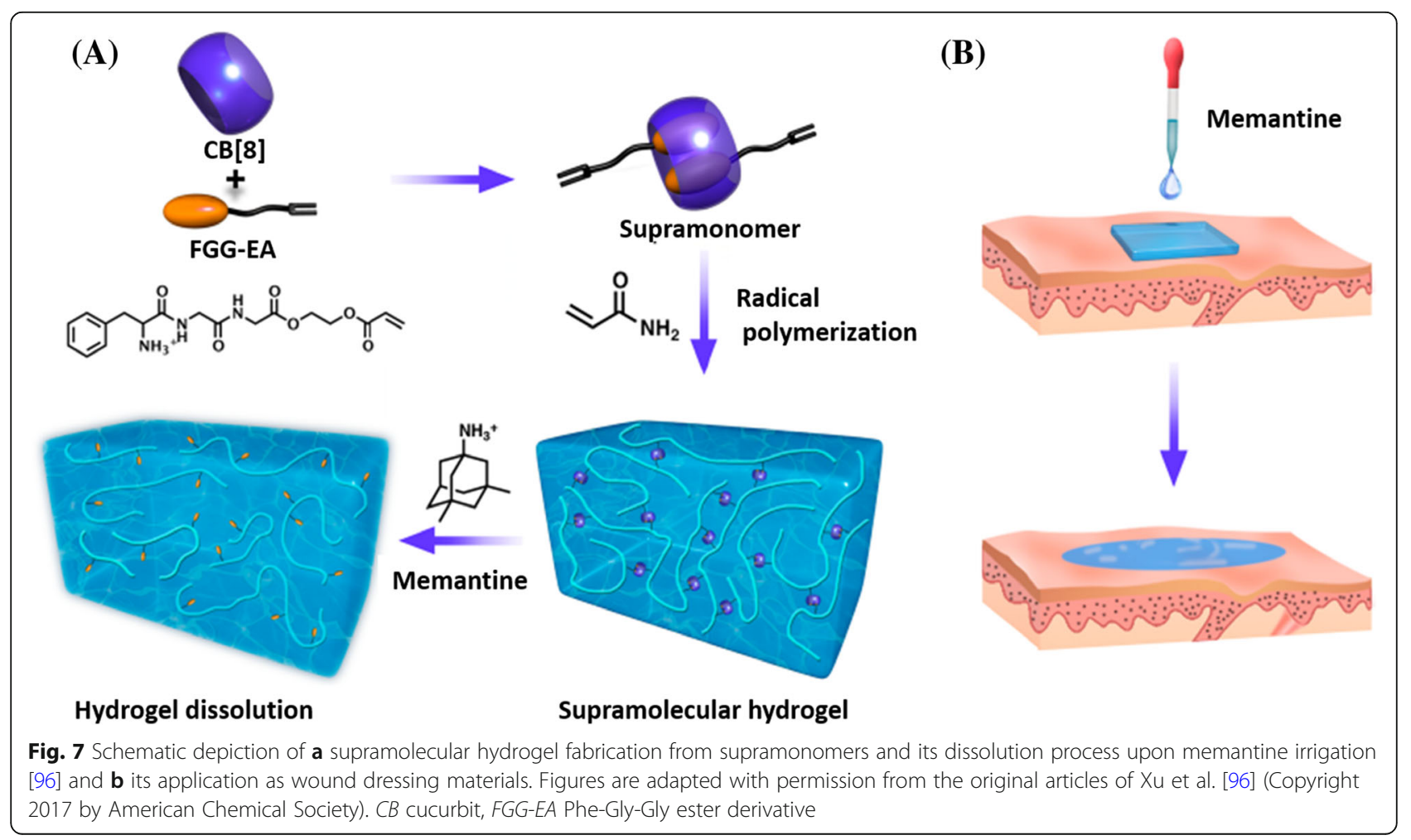


Moreover, due to the fact that these hydrogels are composed of dynamic and reversible supramolecular cross-linkers, the supramolecular hydrogels will dissolve quickly (within $2 \mathrm{~min}$ ) with memantine. As a result, the stimuli-dissolving supramolecular hydrogels will present a new generation of wound dressing materials.

Supramolecular hydrogels have been widely researched as wound dressing due to the advantages of degradable, injectable, adjustable gelation process, simple preparation, and without chemical reactions. More important, this self-assembled supramolecular hydrogels as wound dressing can be mildly removed after finishing its work. However, it is difficult to control self-assembly process. The optimization of the amphiphilic polymers of building blocks provides a possible for controlled self-assembly process, while the gelation time and dissolved response speed need to be further improved.

\section{Conclusions}

In this paper, four popular strategies for preparation of dissolvable chemically cross-linked hydrogels, environment-sensitive physically cross-linked hydrogels and supramolecular self-assembly hydrogels are introduced. All of them provide economical and effective methods for the synthesis of controlled and on-demand dissolving hydrogels for in vivo applications.

It should be pointed out that different types of wounds and different stages of the same wound have different requirements for hydrogel dressings, and it is difficult for a single material to meet the complex needs of the wound. Therefore, multifunctional dressings, which can be prepared by combining different functional materials, open up a method to meet the various demands in the healing process. Besides, new cross-linking and dissolution strategies should be considered in designing hydrogels for clinical purposes. Continued study and development of hydrogels is of great interest. Overall, the exploration of new type of on-demand dissolvable hydrogels is an area that displays the creativity of both chemists and biologist in materials and chemical biology.

\section{Acknowledgements}

Not applicable.

\section{Funding}

This work is supported by the Science and Technology Innovation Plan of Southwest Hospital (No. SWH2016ZDCX2014 and SWH2017ZDCX1001), Third Military Medical University (Grant No. 2016XPY12).

\section{Availability of data and materials}

Data sharing is not applicable to this article as no datasets were generated.

\section{Authors' contributions}

$\mathrm{HL}, \mathrm{DH}$, and JD contributed to the peer-reviewing and writing of the manuscript. All authors read and approved the final manuscript.
Ethics approval and consent to participate

Not applicable.

\section{Consent for publication}

Not applicable.

\section{Competing interests}

The authors declare that they have no competing interests.

\section{Author details}

'Department of Dermatology, Chongqing Traditional Chinese Medicine Hospital, Chongqing 400021, China. ${ }^{2}$ Institute of Burn Research, South-West Hospital, State Key Lab of Trauma, Burn and Combined Injury, Third Military Medical University (Army Medical University), Gaotanyan Road No. 30, Shapingba District, Chongqing 400038, China. ${ }^{3}$ Department of Breast Surgery, Southwest Hospital, Third Military Medical University (Army Medial University), Chongqing 400038, China. ${ }^{4}$ Department of Respiratory, Wuxi Country People's Hospital, Chongqing 405800, China.

Received: 23 July 2018 Accepted: 11 December 2018

Published online: 29 December 2018

\section{References}

1. Robbins JM, Strauss G, Aron D, Long J, Kuba J, Kaplan Y. Mortality rates and diabetic foot ulcers. J Am Podiatr Med Assoc. 2008:98:489-93.

2. Noor S, Zubair M, Ahmad J. Diabetic foot ulcer: A review on pathophysiology, classification and microbial etiology. Diabetes Metab. Syndr. 2015;3:192-9.

3. Liu X, Chen B, Xiaoling R, Liao Q, Xie W, Zhang Y, et al. The practice of standardized management in wound/stoma care clinic. J Nurs Sci. 2017:22:41-3.

4. Pop MA, Almquist BD. Biomaterials: a potential pathway to healing chronic wounds? Exp Dermatol. 2017:26:760-4.

5. Madaghiele M, Demitri C, Sannino A, Ambrosio L. Polymeric hydrogels for burn wound care: advanced skin wound dressings and regenerative templates. Burns Trauma. 2014;2:153-61.

6. Martin C, Low WL, Amin MC, Radecka I, Raj P, Kenward K. Current trends in the development of wound dressings, biomaterials and devices. Pharm Pat Anal. 2013:2:341-59.

7. Wasiak J, Cleland H, Campbell F. Dressings for superficial and partial thickness burns. Cochrane Database Syst Rev. 2013:3:CD002106.

8. Cai EZ, Teo EY, Jing L, Yun PK, Qian TS, Wen F, et al. Bio-conjugated polycaprolactone membranes: a novel wound dressing. Arch Plast Surg 2014;41:638-46.

9. Queen D, Evans JH, Gaylor JDS, Courtney JM, Reid WH. Burn wound dressings-a review. Burns. 1987:13:218-28.

10. Atchison NE, Osgood PF, Carr DB, Szyfelbein SK. Pain during burn dressing change in children: relationship to burn area, depth and analgesic regimens. Pain. 1991;47:41-5.

11. Rippon M, Davies P, White R. Taking the trauma out of wound care: the importance of undisturbed healing. J Wound Care. 2012;21:359-60 362, $364-8$.

12. Sun G, Feng C, Kong M, Cheng X, Bing J, Xia G, et al. Development of partdissolvable chitosan fibers with surface $\mathrm{N}$-succinylation for wound care dressing. Front Mater Sci. 2015:9:272-81.

13. Linardatos G, Bekiari V, Bokias G. Organic hydrogels as potential sorbent materials for water purification. EGU Gen Assem Conf. 2014;16:16564-1.

14. Malda J, Visser J, Melchels FP, Jüngst T, Hennink WE, Dhert WJA, et al. 25th anniversary article: engineering hydrogels for biofabrication. Adv Mater. 2013;25:5011-28.

15. Spagnol C, Rodrigues FHA, Neto AGVC, Pereira AGB, Fajardoa AR, Rubira AF, et al. Nanocomposites based on poly (acrylamide-co-acrylate) and cellulose nanowhiskers. Eur Polym J. 2012;48:454-63.

16. Gaballa HA, Geever LM, Killion JA, Higginbotham CL. Synthesis and characterization of physically crosslinked $\mathrm{N}$-vinylcaprolactam, acrylic acid, methacrylic acid, and N,N -dimethylacrylamide hydrogels. J Polym Sci Polym Phys. 2013;51:1555-64

17. Cascone MG, Sim B, Downes S. Blends of synthetic and natural polymers as drug delivery systems for growth hormone. Biomaterials. 1995;16:569-74.

18. Simes S, Figueiras A, Veiga F. Modular hydrogels for drug delivery. Biomater Nanobiotechnol. 2012;3:185-99. 
19. Tian K, Shao Z, Chen $X$. Natural electroactive hydrogel from soy protein isolation. Biomacromolecules. 2010;11:3638-43.

20. Peppas NA, Bures P, Leobandung W, Ichikawa H. Hydrogels in pharmaceutical formulations. Eur J Pharm Biopharm. 2000;50:27-46.

21. Tian $D$, Blacher $S$, Dubois $P$, Jérôme R. Biodegradable and biocompatible inorganic-organic hybrid materials: 2. Dynamic mechanical properties, structure and morphology. Polymer. 1998;39:855-64.

22. Lu Q, Bai S, Ding Z, Guo H, Shao Z, Zhu H, et al. Hydrogel assembly with hierarchical Alignment by balancing electrostatic forces. Adv Mater Interfaces. 2016;3:1500687-93.

23. Cruzacuña R, Quirós M, Farkas AE, Dedhia PH, Huang S, Siuda D, et al. Synthetic hydrogels for human intestinal organoid generation and colonic wound repair. Nat Cell Biol. 2017:19:1326.

24. Qian W, Yan C, He D, Yu X, Yuan L, Liu M, et al. pH-triggered chargereversible of glycol chitosan conjugated carboxyl graphene for enhancing photothermal ablation of focal infection. Acta Biomater. 2018;69:256-64.

25. Huang $Y$, Ma $Y$, Chen $Y$, Wu X, Fang L, Zhu Z, et al. Target-responsive DNAzyme cross-linked hydrogel for visual quantitative detection of lead. Anal Chem. 2014:86:11434-9.

26. Kim J, Kong YP, Niedzielski SM, Singh RK, Putnam AJ, Shikanov A. Characterization of the crosslinking kinetics of multi-arm poly (ethylene glycol) hydrogels formed via Michael-type addition. Soft Matter. 2016;12:2076-85.

27. Li X, Tsutsui $Y$, Matsunaga T, Shibayama M, Chung U, Sakai T. Precise control and prediction of hydrogel degradation behavior. Macromolecules. 2011;44: 3567-71.

28. Ehrbar M, Rizzi SC, Schoenmakers RG, Miguel BS, Hubbell JA, Weber FE, et al. Biomolecular hydrogels formed and degraded via site-specific enzymatic reactions. Biomacromolecules. 2007:8:3000-7.

29. Liechty WB, Kryscio DR, Slaughter BV, Peppas NA. Polymers for drug delivery systems. Annu Rev Chem Biomol. 2009:1:149-73.

30. Fernández E, Mijangos C, Guenet JM, Cuberes MT, López D. New hydrogels based on the interpenetration of physical gels of agarose and chemical gels of polyacrylamide. Eur Polym J. 2009;45:932-9.

31. Don TM, Huang ML, Chiu AC, Kuo KH, Chiu WY, Chiu LH. Preparation of thermo-responsive acrylic hydrogels useful for the application in transdermal drug delivery systems. Mater Chem Phys. 2008;107:266-73.

32. Hu Y, Du Z, Deng X, Wang T, Yang Z, Zhou W, et al. Dual physically crosslinked hydrogels with high stretchability, toughness, and good selfrecoverability. Macromolecules. 2016;49:5660-8.

33. Ning J, Li G, Haraguchi K. Synthesis of highly stretchable, mechanically tough, zwitterionic sulfobetaine nanocomposite gels with controlled thermosensitivities. Macromolecules. 2013;46:5317-28.

34. Bracher PJ, Snyder PW, Bohall BR, Whitesides GM. The relative rates of thiolthioester exchange and hydrolysis for alkyl and aryl thioalkanoates in water. Orig Life Evol Biosph. 2011;41:399-412.

35. Hupe DJ, Jencks WP. Nonlinear structure-reactivity correlations. Acyl transfer between sulfur and oxygen nucleophiles. J Am Chem Soc. 1977;99:451-64.

36. Konieczynska MD, Grinstaff MW. On-demand dissolution of chemically crosslinked hydrogels. Acc Chem Res. 2017;50:151-60.

37. Ghobril C, Charoen K, Rodriguez EK, Nazarian A, Grinstaff MW. A dendritic thioester hydrogel based on thiol-thioester exchange as a dissolvable sealant system for wound closure. Angew Chem Int Ed. 2013;52:14070-4.

38. Hirst AR, Smith DK. Dendritic gelators. Top Curr Chem. 2005;256:237-73.

39. Kazzouli SE, Mignani S, Bousmina M, Majoral J-P. Chemlnform abstract: dendrimer therapeutics: covalent and ionic attachments. New J Chem. 2012;36:227-40.

40. Mintzer MA, Grinstaff MW. Biomedical applications of dendrimers: a tutorial. Chem Soc Rev. 2011:40:173-90.

41. Konieczynska MD, Villa-Camacho JC, Ghobril C, Perez-Viloria M, Tevis KM, Blessing WA, et al. On-demand dissolution of a dendritic hydrogel-based dressing for second-degree burn wounds through thiol\&ndash;thioester exchange reaction. Angew Chem Int Ed. 2016;128:10138-41.

42. Wilson JM, Wu D, Motiudegrood R, Hupe DJ. A spectrophotometric method for studying the rates of reaction of disulfides with protein thiol groups applied to bovine serum albumin. J Am Chem Soc. 1980;102:359-63.

43. Houk J, Whitesides GM. ChemInform abstract: structure-reactivity relations for thiol-disulfide interchange. J Am Chem Soc. 1987;109:6825-36.

44. Palacio H, Otálvaro F, Giraldo LF, Ponchel G, Segurasánchez F. Chitosanacrylic polymeric nanoparticles with dynamic covalent bonds. Synthesis and stimuli behavior. Chem Pharm Bull. 2017;62:1132-43.

45. Hisano N, Morikawa N, Iwata $H$, Ikada Y. Entrapment of islets into reversible disulfide hydrogels. J Biomed Mater Res. 1998;40:115-23.
46. Gyarmati B, Vajna B, Némethy Á, László K, Szilágyi A. Redox- and pHresponsive cysteamine-modified poly (aspartic acid) showing a reversible sol-gel transition. Macromol Biosci. 2013;13:633-40.

47. Anumolu SNS, Menjoge AR, Deshmukh M, Gerecke D, Stein S, Laskin J. Doxycycline hydrogels with reversible disulfide crosslinks for dermal wound healing of mustard injuries. Biomaterials. 2011;32:1204-17.

48. Baldwin AD, Kiick KL. Reversible maleimide-thiol adducts yield glutathionesensitive poly (ethylene glycol)-heparin hydrogels. Polym Chem. 2013;4:133-43.

49. Kharkar PM, Kiick KL, Kloxin AM. Design of thiol- and lght-sensitive degradable hydrogels using michael-type addition reactions. Polym Chem. 2015:6:5565-74

50. Kharkar PM, Kloxin AM, Kiick KL. Dually degradable click hydrogels for controlled degradation and protein release. J Mater Chem B. 2014;2:5511-21.

51. Koehler KC, Anseth KS, Bowman CN. Diels-alder mediated controlled release from a poly (ethylene glycol) based hydrogel. Biomacromolecules. 2013;14:538-47

52. Wei HL, Yang Z, Zheng LM, Shen YM. Thermosensitive hydrogels synthesized by fast Diels-Alder reaction in water. Polymer. 2009;50:2836-40.

53. Higginson CJ, Kim SY, Peláezfernández M, Fernándeznieves A, Finn MG. Modular degradable hydrogels based on thiol-reactive oxanorbornadiene linkers. J Am Chem Soc. 2015;137:4984-7 https://pubs.acs.org/doi/10.1021/ jacs.5b02708.

54. Kirchhof S, Brandl FP, Hammer N, Goepferich AM. Investigation of the DielsAlder reaction as a cross-linking mechanism for degradable poly (ethylene glycol) based hydrogels. J Mater Chem B. 2013;1:4855-64.

55. Loveren HV, Goettsch W, Slob W, Garssen J. Risk assessment for the harmful effects of UVB radiation on the immunological resistance to infectious diseases. Arch Toxicol Suppl. 1996:106:21-8.

56. Takashima Y, Sawa Y, Iwaso K. Supramolecular materials cross-linked by host-guest inclusion complexes: the effect of side chain molecules on mechanical properties. Macromolecules. 2017:8:3254-61.

57. Gong Z, Ding S, Yin Y, Cui Y, Yao K. Optimized design of hydrogels for tissue engineering. Chem Ind Eng Prog. 2008;27:1743-9.

58. Xu L, Li X, Zhai M, Huang L, Peng J, Li J, et al. Ion-specific swelling of poly (styrene sulfonic acid) hydrogel. J Phys Chem B. 2007;111:3391-7.

59. Kim J J, Park K. Smart hydrogels for bioseparation. Bioseparation. 1998:7: 177-84.5.

60. Narasimhan B, Peppas NA. Disentanglement and reptation during dissolution of rubbery polymers. J Polym Sci Polym Phys. 2015;34:947-61.

61. Narasimhan B, Peppas NA. On the importance of chain reptation in models of dissolution of glassy polymers. Macromolecules. 1996;29:3283-91.

62. Mallapragada SK, Peppas NA. Dissolution mechanism of semicrystalline poly (vinyl alcohol) in water. J Polym Sci Polym Phys. 2015;34:1339-46.

63. Gong Z, Zhang G, Zeng X, Li J, Li G, Huang W, et al. High-strength, tough, fatigue resistant and self-healing hydrogel based on dual physically crosslinked network. ACS Appl Mater Interfaces. 2016;8:24030-7.

64. Tamesue S, Ohtani M, Yamada K, Ishida Y, Spruell JM, Lynd NA, et al. Linear versus dendritic molecular binders for hydrogel network formation with clay nanosheets: studies with ABA triblock copolyethers carrying guanidinium ion pendants. J Am Chem Soc. 2013;135:15650-5.

65. Zhao SP, Zhang LM, Ma D, Yang C, Yan L. Fabrication of novel supramolecular hydrogels with high mechanical strength and adjustable thermosensitivity. J Phys Chem B. 2006:110:16503-7.

66. Bae Y, Fukushima S, Harada A, Dr KK. Design of environment-sensitive supramolecular assemblies for intracellular drug delivery: Polymeric micelles that are responsive to intracellular pH change. Chem Int Ed. 2003;42:4640-3.

67. Garg T, Singh S, Goyal AK. Stimuli-sensitive hydrogels: an excellent carrier for drug and cell delivery. Crit Rev Ther Drug. 2013;30:369-409.

68. Bhattarai N, Ramay H, Gunn J, Matsen F, Zhang M. PEG-grafted chitosan as an injectable thermosensitive hydrogel for sustained protein release. Macromol Biosci. 2005;103:609-24.

69. Grassi G, Farra R, Caliceti DP, Guarnieri G, Salmaso S, Carenza M, et al. Temperature-sensitive hydrogels. Am J Drug Deliv. 2005;3:239-51.

70. Zhang $X$, Ren S, Zhu J, Lei T. Preparation and characterization of cellulose nanocrystals based supramolecular hydrogels. Henan Sci. 2016;1 1:1812-7.

71. Park MH, Joo MK, Choi BG, Jeong B. Biodegradable thermogels. Acc Chem Res. 2012;45:424-33

72. Qiu Y, Park K. Environment-sensitive hydrogels for drug delivery. Adv Drug Deliv Rev. 2012;64:49-60.

73. Nguyen MK, Lee DS. Injectable biodegradable hydrogels. Macromol Biosci. 2010;10:563-79. 
74. Bhattarai N, Gunn J, Zhang M. Chitosan-based hydrogels for controlled, localized drug delivery. Adv Drug Deliv Rev. 2010;62:83-99.

75. Xia Y, Wang J, Xu S, Liao Q, Zhu X, Wang Y, et al. Dually stimuliresponsive hyperbranched polyethylenimine with LCST transition based on hydrophilic\&ndash;hydrophobic balance. J Appl Polym Sci. 2012;127: 3249-55.

76. Hirotsu S. Coexistence of phases and the nature of first-order phase transition in poly-N-isopropylacrylamide gels. Macromolecules. 1993;37: 3415-24.

77. Chenite A, Chaput C, Wang D, Combes C, Buschmann MD, Hoemann CD, et al. Novel injectable neutral solutions of chitosan form biodegradable gels in situ. Biomaterials. 2000;21:2155-61.

78. Philippova OE, Volkov EV, Sitnikova NL, Khokhlov AR, Desbrieres J, Rinaudo M. Two types of hydrophobic aggregates in aqueous solutions of chitosan and its hydrophobic derivative. Biomacromolecules. 2001;2:483-90.

79. Schatz C, Viton C, Delair T, Pichot C, Domard A. Typical physicochemical behaviors of chitosan in aqueous solution. Biomacromolecules. 2003;4:641-8.

80. Shigemasa Y, Minami S. Applications of chitin and chitosan for biomaterials. Biotechnol Genet Eng Rev. 1996;13:383-420.

81. Rao SB, Sharma CP. Use of chitosan as a biomaterial: studies on its safety and hemostatic potential. J Biomed Mater Res. 1997;34:21-8.

82. Falamarzian $\mathrm{M}$, Varshosaz J. The effect of structural canges on swelling kinetics of polybasic/ hydrophobic pH-sensitive hydrogels. Drug Dev Ind Pharm. 1998;24:667-9.

83. Lee SJ, Park K. Synthesis and characterization of sol-gel phase-reversible hydrogels sensitive to glucose. J Mol Recognit. 1996;9:549-57.

84. Namdeo M, Bajpai SK, Kakkar S. Preparation of a magnetic-field-sensitive hydrogel and preliminary study of its drug release behavior. J Biomater Sci Polym Ed. 2009;20:1747-61

85. Jochum FD, Theato P. Temperature and light sensitive copolymers containing azobenzene moieties prepared via a polymer analogous reaction. Polymer. 2009;50:3079-85.

86. Clemente MJ, Tejedor RM, Romero P, Fitremann J, Oriol L. Maltose-based gelators having azobenzene as light-sensitive unit. RSC Adv. 2012;2:11419-31.

87. Song B, Zhao J, Wang B, Jiang R. Synthesis and self-assembly of new lightsensitive Gemini surfactants containing an azobenzene group. Colloids Surf A. 2009:352:24-30.

88. Zhang M, Xu D, Yan X, Chen J, Dong S, Zheng B, et al. Self-healing supramolecular gels formed by crown ether based host-guest interactions. Angew Chem Int Ed. 2012;124:7117-21.

89. Komatsu H, Tsukiji S, Ikeda M, Hamachi I. Stiff, Multistimuli-responsive supramolecular hydrogels as unique molds for 2D/3D microarchitectures of live cells. Chem Asian J. 2011;6:2368-75.

90. Wang Y, Xu H, Zhang X. Tuning the Amphiphilicity of Building Blocks: Controlled self-assembly and disassembly for functional supramolecular materials. Adv Mater. 2010;21:2849-64.

91. Guan Y, Zhao HB, Yu LX, Chen SC, Wang YZ. Multi-stimuli sensitive supramolecular hydrogel formed by host-guest interaction between PNIPAM-Azo and cyclodextrin dimers. RSC Adv. 2014;4:4955-9.

92. Manakker FVD, Pot MVD, Vermonden T, Nostrum CFV, Hennink WE. Selfassembling hydrogels based on $\beta$-cyclodextrin/cholesterol inclusion complexes. Macromolecules. 2008:41:1766-73.

93. Peng K, Tomatsu I, Kros A. Light controlled protein release from a supramolecular hydrogel. Chem Commun. 2010;46:4094-6.

94. Zhao YL, Stoddart JF. Azobenzene-based light-responsive hydrogel system. Langmuir. 2009;25:8442-6.

95. Tomatsu I, Akihito Hashidzume A, Harada A. Photoresponsive hydroge system using molecular recognition of a-cyclodextrin. Macromolecules. 2005;38:5223-7.

96. Xu W, Qiao S, Xu J, Serpe MJ, Xi Z. Supramolecular hydrogels fabricated from supramonomers: a novel wound dressing material. ACS Appl Mater Interfaces. 2017;9:11368-72

Ready to submit your research? Choose BMC and benefit from:

- fast, convenient online submission

- thorough peer review by experienced researchers in your field

- rapid publication on acceptance

- support for research data, including large and complex data types

- gold Open Access which fosters wider collaboration and increased citations

- maximum visibility for your research: over $100 \mathrm{M}$ website views per year

At $\mathrm{BMC}$, research is always in progress.

Learn more biomedcentral.com/submissions 